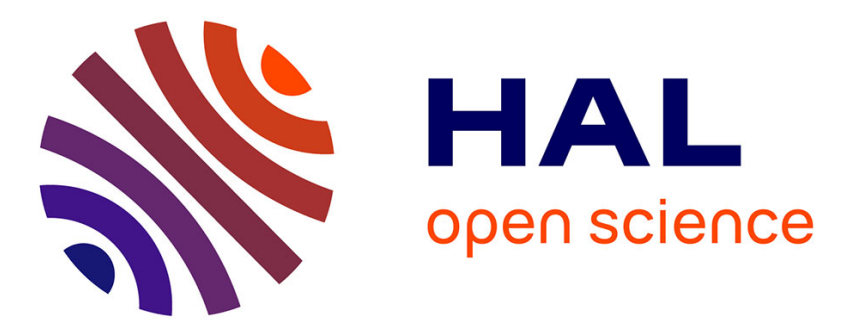

\title{
Cloud-Based Decision Support Ecosystem for Renewable Energy Providers
}

\author{
Ioana Andreea Stănescu, Antoniu Ştefan, Florin Gheorghe Filip
}

\section{To cite this version:}

Ioana Andreea Stănescu, Antoniu Ştefan, Florin Gheorghe Filip. Cloud-Based Decision Support Ecosystem for Renewable Energy Providers. 6th Doctoral Conference on Computing, Electrical and Industrial Systems (DoCEIS), Apr 2015, Costa de Caparica, Portugal. pp.405-412, 10.1007/978-3319-16766-4_43. hal-01343509

\section{HAL Id: hal-01343509 \\ https://inria.hal.science/hal-01343509}

Submitted on 8 Jul 2016

HAL is a multi-disciplinary open access archive for the deposit and dissemination of scientific research documents, whether they are published or not. The documents may come from teaching and research institutions in France or abroad, or from public or private research centers.
L'archive ouverte pluridisciplinaire HAL, est destinée au dépôt et à la diffusion de documents scientifiques de niveau recherche, publiés ou non, émanant des établissements d'enseignement et de recherche français ou étrangers, des laboratoires publics ou privés.

\section{(c)(1)}

Distributed under a Creative Commons Attribution| 4.0 International License 


\title{
Cloud-Based Decision Support Ecosystem for Renewable Energy Providers
}

\author{
Ioana Andreea Stănescu ${ }^{1}$, Antoniu Ștefan ${ }^{1}$, \\ and Florin Gheorghe Filip ${ }^{2}$ \\ ${ }^{1}$ Advanced Technology Systems, 1 Tineretului Str., Targoviste, 130029, Romania \\ \{Ioana.Stanescu, Antoniu.Stefan\}@ats.com.ro \\ ${ }^{2}$ Romanian Academy-INCE, 125 Calea Victoriei, Bucharest, 010071, Romania \\ \{ffilip\}@acad.ro
}

\begin{abstract}
The increasing complexity of decision making environments requires new approaches that can improve the efficiency, the effectiveness and the quality of the decision making processes. Cloud-based Decision Support Ecosystems (DSE) create the premises for the next generation of DSS, by modeling dynamic system architectures and customizable decision layers that instantiate a new level of independence at end-user level. End-users are able to connect new data sources to the decision making processes without assistance from software developers, while maintain consistency, to build more relevant decision environments. The authors discuss key challenges associated with the DSE and present the design premises of a cloud-based DSE for renewable energy providers. The paper builds upon the $\mathrm{PhD}$ research carried out within the INDESEN Project, funded by Unitatea Executiva pentru Finantarea Invatamantului Superior, a Cercetării, Dezvoltării si Inovarii (UEFISCDI) through the Romanian Partnership Program.
\end{abstract}

Keywords: dynamic architecture, cloud computing, renewable energy.

\section{Introduction}

A Decision Support System (DSS) should enable decision makers to efficiently manage the increasing complexity, rapid changes and emergent risks of today's business environments. However, while it is easy to highlight the potential benefits of DSSs, it is often harder to deliver them in practice. Technology and knowledge advance at a rapid pace, but the complexity of the decision making environments also increases. The speed and the quality of decision making processes have to be enhanced at a faster rate. Beside context specific issues, decision makers also have to overcome collateral challenges associated with information overload and information distortion.

Nowadays, decision making does not rely on a single tool, but on a heterogeneous mix of systems of systems that support decision making processes. However, even if these systems are integrated and interoperable, they still reply on a static architecture that end-users cannot customize according to their needs. The unified management of all these DSSs coupled with the reduction of redundancies and end-user development 
represent a significant challenge. How can existing decision support technologies be improved considering emerging technologies and practices?

Web technologies and mobile communication, increased processing power, cloud infrastructures, and intelligent devices have created the premises for DSSs that enable decision makers better their performance. There are many opportunities to employ new information technologies to improve decision making processes.

In this context, the authors advance the notion of Decision Support Ecosystems (DSE) that fundament the design and development of dynamic system architectures, and that introduces for end-users a new level of independence from system developers. The design premises of a cloud-based DSE for renewable energy providers are presented, and related challenges are discussed.

\section{Cloud-based Decision Support Ecosystems}

The approach proposed in this paper builds upon cloud computing developments that enables the delivery of computing resources as a service. Cloud solutions implement horizontal scalable architectures, dynamic sizing (automatically adding and removing server instances), zero downtime architectures, dynamic failure detection and recovery architecture, etc [1], [2]. Cloud capabilities, especially dynamic sizing, answer to a critical issue that concern the use of the term "ecosystem" in connection to software: absence of intention [3]. Cloud services are key to building autoadaptable software ecosystems. Because cloud environments are able to use as many servers as necessary to optimally respond to the cost and the timing constraints of an application [4], they are able to nurture the natural evolution of DSEs.

In the case of a dynamic system architecture, end-users are able to integrate their own data sources and they are able to customize the decision flows to integrate them. The authors have considered an Intelligent Decision Support and Control System for Low Voltage Grids with Distributed Power Generation from Renewable Energy Sources (INDESEN) to validate their premises.

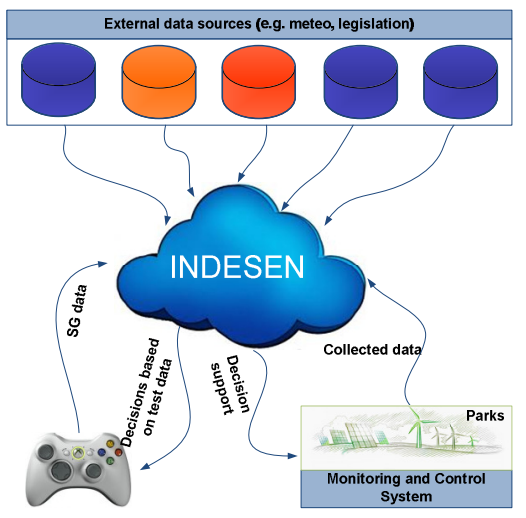

Fig. 1. Cloud-centric data flow. 
INDESEN is offered as a cloud based service. The service is open and it can interconnect several data sources with the actors that take the decisions based on the analyses carried out by the system. Data communication is based on open Web services standards SOAP (Simple Object Access Protocol), REST (Representational State Transfer).

The system is designed as a cloud centric solution that stores and processed data centrally. This approach increases the adoption by lowering upfront costs and overall Total Cost of Ownership. Another contributing factor in choosing a cloud based solution is the large geographical distribution of renewable energy power plants which can only be efficiently managed through a centralized solution.

For data collection purposes, the system defined a set of API functions that can be used by third-party developers, as well as a set of standard software agents that can be deployed on site and feed data from proprietary hardware to the cloud.

\section{State-of-the-Art}

Decision capabilities have been supported by a large range of systems ranging from Executive Information Systems, Expert Systems and Decision Support Systems to Business Intelligence, Business Analytics, Business Activity Monitoring, Business Performance Monitoring [5], Knowledge Based Systems [6], Creativity Enhancing Systems [7], etc.

Advances in Information Technology (IT) have brought solutions to many DSS issues and at the same time they also generated new opportunities and challenges for DSS developers. System integration and interoperability have significantly enhanced the performance, efficiency and quality of decision processes [8].

For the purpose of this paper, decision support tools used in the electrical energy field have been considered. In this context, Supervisory Control and Data Acquisition (SCADA) based solutions have been the first to be designed and developed to monitor and control renewable energy plants [9]. The early developments of such systems offered a friendly interface for controlling systems that contain Programmable Logic Controllers (PLC) and mainly aimed to assist the human operators in routine processes [10]. More complex solutions have followed providing functions that were able to provide monitoring and operational evaluation of remote Renewable Energy Sources [11].

Considering the specific requirements related to renewable energy production, storage, and distribution, research efforts in recent years have focuses on more advanced solutions able to facilitate renewable energy management and decisionmaking for independent or connected to public supply networks. Research has been carried out on renewable energy monitoring [12]; interoperability issues [8]; algorithms for fast oscillation detection [13]; environmental monitoring [14], linear and non-linear optimization algorithms used in renewable energy sources [15]; production of scientific knowledge on renewable energy [16]. Research addressing decision-making concerned energy availability for consumers, safety power supplying; reducing costs and maximizing generation [17]. 


\section{Decision Support Ecosystems}

\subsection{Perspectives on Ecosystems}

In recent years, ecosystems have gained momentum as an important field of research fueled by new business models [18]. A wide variety of ecosystems ranging from software to business and social ecosystems have been modeled. For the purpose of this research software and business ecosystems have been considered.

Software ecosystems are defined as a set of software solutions that enable, support and automate the activities and the transactions of the actors that operate in a business environment [19]. Considering the multitude of devices and applications that are used in a renewable energy plant, the adoption of an ecosystem approach has the potential to provide the prerequisites for better decision-making processes.

Companies have changed the focus from rear-view mirror analysis (studying data from the past) to looking through the windshield practices (using data to predict future patterns) because the ability to anticipate can bring significant advantages [20]. For renewable energy providers the ability to predict is even more relevant, as based on prediction they can better estimate energy prediction (based on more accurate weather patterns), deploy resources more effectively, reduce downtime, adjust staff levels, etc. Building business analytics ecosystems stands out as an essential component of future applications.

\subsection{Key Challenges for DSE End-Users}

The complexity of the decision-making environments has increased due to information overload, distortion of information, the need for faster, more accurate decisions, the challenging business environments, increased costs, etc. The capacity to access the right information at the right time, to retrieve knowledge, to analyse data and documents, as well as the ability to anticipate have become crucial for managers.

The premises for the DSE design have emerged from a set of challenges associated with existing DSSs. Power [5] has identified that:

1) DSS employ complex hardware and software technologies, and decision makers need computing and software knowledge to be able to operate such systems;

2) Decision makers need to manage rapidly changing environments, including changes associated with context environments and technology evolution;

3) There is a growing need for end-user development of DSS.

4) Decision makers need to understand the upside benefits, the downside risks, and the possibilities of further development.

Currently, DSS have a static architecture that translates into a limited flexibility at end user level. End users cannot perform changes in the system without assistance from developers even if they have advanced IT skills. Even if end users are able to connect to external data sources, the system logic is not customizable and the new sources cannot be integrated into decisional flows. 


\subsection{DSE for Renewable Energy Providers}

The decision-making processes in the renewable energy field are extremely challenging as they are based on masses of details concerning many different issues that require analysis and management. Therefore, decision makers use different tools to monitor and control, to carry out diagnosis and prediction, and to make decisions. They also rely on a wide range of data sources to fundament their decisions. These data sources are difficult to predict when the decision support tool is developed. Even if initial, generic data sources exist, for better decisions DSE end users need to connect to more data sources.

The research reported in this paper addresses the above-mentioned challenge and documents the decision-making processes associated with the management of renewable energy plants with the purpose of supporting the design of a cloud- and knowledge-based Intelligent Decision Support and Control System for Low Voltage Grids with Distributed Power Generation from Renewable Energy Sources (INDESEN) where end users can integrate into decision flows any data sources that comply to accepted formats (Fig. 2).

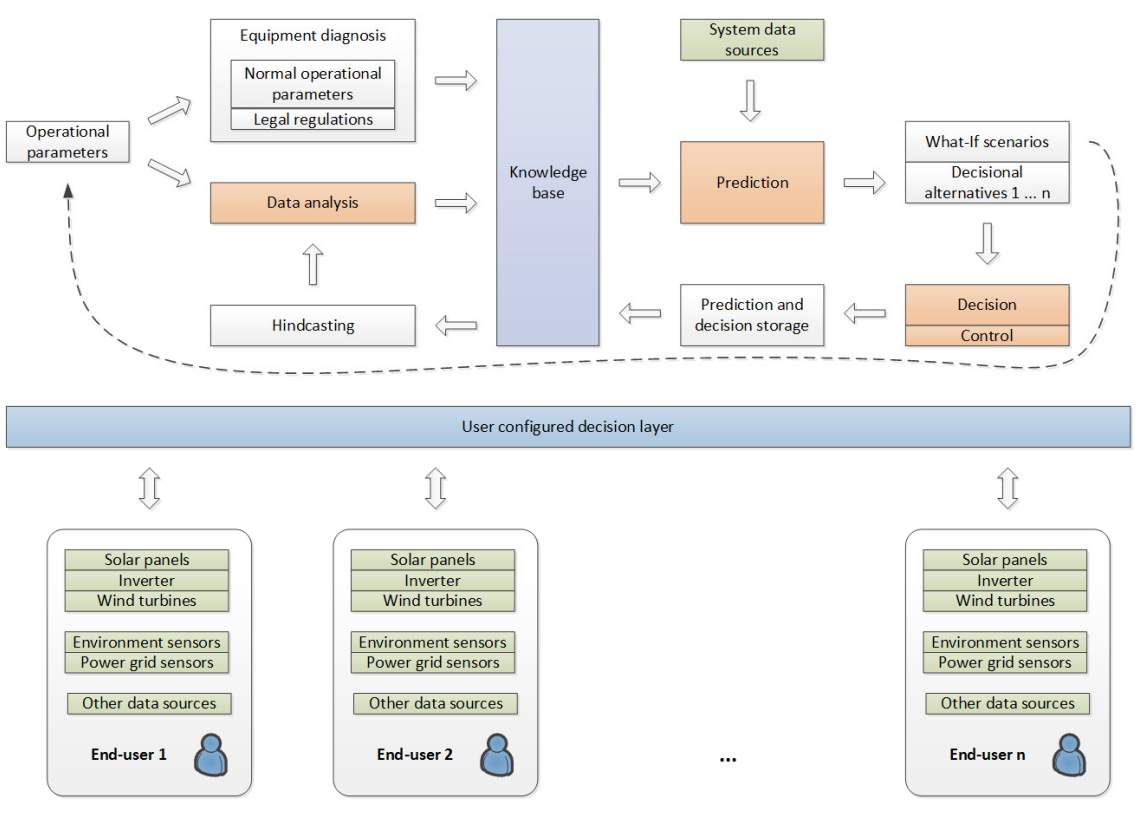

Fig. 2. INDESEN end user customizable decision layer.

INDESEN is designed to integrate the following modules:

- The Monitoring Module. Enables real-time tracking of the parameters that monitor the electric energy quality and the environmental factors. The data will be stored in the INDESEN database and will fundament the development of the knowledge base and the diagnosis of the hardware equipment. 
- The Diagnosis Module. The diagnosis of the equipment and of the causes that led to dysfunctions is carried out in the Diagnoses Module against reference standard values collected from the equipment specifications, the regulatory requirements issued by competent authorities, standards, national and European legislation, etc.

- The Prediction Module. The short-, medium, and long-term prediction is based on internal and external data sources. Data are constantly collected from the equipment and sensors installed in the renewable energy parks and from external weather services. The analysis takes into account the historical data and expert knowledge collected in the system. The capacity to produce electric energy is determined based on factors such as: the periodicity (day/ night; summer/ winter) of the environmental factors (solar radiation, temperature, wind speed), the equipment wear in time, etc.

- The Decision Module. The system will generate alternative decision scenarios that the decision-makers can choose from. For each scenario the system will present a synthesis of the rationale behind it build on historical data, current state of the equipment, weather prediction services, expert knowledge, etc.

- The Control Module. The system will allow real-time control of the equipment, in order to increase their efficiency. Decision-makers can intervene to optimize the energy supply/ storage ratio.

End users are able to integrate their own data sources in any of the above mentioned modules of INDESEN. The customizable decision layer maintains the consistency across the system, as end users can define correlations between the new data sources and the decision flows supported by the system. As INDESEN is designed as a cloud-based system, this enables the solution to scale according to the demands. End users will not encounter hardware or software capabilities issues when connected to a large number of new data sources.

\section{Discussion and Conclusion}

The increasing complexity of the decision-making processes in a globalized economy created the need for advanced computerized decision-support ecosystems that enable fact-based decisions, improve decision quality, enhance the efficiency and effectiveness of decision processes, and are able to provide competitive advantage while addresses rapid changes, and emerging risks. Wide access to knowledge management architectures, worldwide real-time access, increased performance and quality, user friendliness, standardized structures, and an easily administered controlling system represent key requirements for DSS. However, without an ecosystem perspective that is based on dynamic software architectures and that integrates cloud-based solutions and end user customizable decision support tools, decision support remain limited.

The authors present the key challenges of current DSS and the premises for the design of an end user customizable cloud- and knowledge-based Intelligent Decision Support and Control System for Low Voltage Grids with Distributed Power 
Generation from Renewable Energy Sources that is able to enhance decision-making processes within future enterprises.

This approach implements a new level of flexibility as end users can integrate data and knowledge sources independently from the system developers and they can reconfigure decision making process to accommodate the sources also without support from developers.

Future work includes the development and testing of the customization features of the DSE at end user level.

Acknowledgments. This research has been carried out within the INDESEN Project "Intelligent decision support and control system for low voltage grids with distributed power generation from renewable energy resources", Contract No. 42/2011, funded through the Romanian Partnership Program.

\section{References}

1. Gregg, B.: Systems Performance: Enterprise and the Cloud. Prentice Hall, New Jersey (2013).

2. Mahmood, Z., Erl, T. Puttini, R.: Cloud Computing: Concepts, Technology \& Architecture. Pretince Hall, Westford (2013).

3. Stallman, R. M.: Free Software, Free Society: The Selected Essays of Richard M. Stallman. http://www.gnu.org/philosophy/words-to-avoid.html\#Ecosystem

4. Marinescu, D. C. Cloud Computing. Elsevier Science, Morgan Kaufmann, Waltham (2013).

5. Power, D. J.: Decision Support Basics. Business Expert Press New York (2009).

6. Zaraté, P.: Integrated and Strategic Advancements in Decision Making Support Systems. IGI Global, Hershey (2012).

7. Delen, D.: Real-World Data Mining: Applied Business Analytics and Decision Making. Pearson FT Press, New Jersey (2014).

8. Stanescu, I.A.; Stefan, A.; Filip, F.G.; Kittl, C.; Lim, T. Interoperability Scenarios in Serious Games Ecosystems: The Impact on FInES. 7th IFAC Conference on Manufacturing Modelling, Management, and Control, Volume \# 7 I Part\# 1, pp. 1334-1339. Elsevier, St. Petersburg (2013).

9. McCrady, S.G.: Practical Procedures for SCADA Software Development. In: Designing SCADA Application Software, Stuart G. McCrady (Ed.), pp. 25-39. Elsevier, Oxford, (2013).

10.Khedkar, M.K., Katti, P.K., George, M.: SCADA based Integrated Operation of Renewable Energy Sources. In: Intl. Conf. of Energy and Informatics, Florida (2008).

11.Papadakis, K., Koutroulis, E., Kalaitzakis, K.: A server database system for remote monitoring and operational evaluation of renewable energy sources plants. Renewable Energy, Volume 30, Issue 11, pp. 1649-1669. Elsevier (2005).

12.Villasevil, F.X., Vigara, J.E., Chiarle, L.: Plug-in driven architecture for renewable energy generation monitoring, Renewable and Sustainable Energy Reviews. Volume 27, pp. 401406. Elsevier (2013).

13.Vanfretti, L., Baudette, M., White, A.: Monitoring and Control of Renewable Energy Sources using Synchronized Phasor Measurements. Renewable Energy Integration, pp. 413428 Elsevier (2014).

14.Garel, E., Rey, C.C., Ferreira, O., van Koningsveld, M.: Applicability of the "Frame of Reference" approach for environmental monitoring of offshore renewable energy projects. Journal of Environmental Management, Volume 141, pp. 16-28. Elsevier (2014). 
406 I A. Stănescu, A. Ștefan and F. G. Filip

15.Iqbal, M., Azam, M., Naeem, M., Khwaja, A.S., Anpalagan, A.: Optimization classification, algorithms and tools for renewable energy: A review. Renewable and Sustainable Energy Reviews, Volume 39, pp. 640-654. Elsevier (2014).

16.Rizzi, F., van Eck, N.J., Frey, M.: The production of scientific knowledge on renewable energies: Worldwide trends, dynamics and challenges and implications for management. Renewable Energy, Volume 62, pp. 657-671. Elsevier (2014).

17.Dumitru, C.D., Gligor, A.: SCADA Based Software for Renewable Energy Management System. Procedia Economics and Finance, Volume 3, pp. 262-267, Targu Mures (2012).

18.Hanssen, G.K., Dyba, T.: Theoretical foundations of software ecosystems. In: Workshop on Software Ecosystems, pp. 6-17. Cambridge (2012).

19.Bosch, J.: From Software Product Lines to Software Ecosystems. In: 13th International Software Product Line Conference, San Francisco (2009).

20.Pring, B., Roehrig, P., Frank, M.: Code Halos: How the Digital Lives of People, Things, and Organizations are Changing the Rules of Business. John Wiley \& Sons, New Jersey (2014). 